\title{
What have we learnt from the COVID-19 epidemic? Considerations of a troubled editor after two troubled years
}

\author{
Giorgina Barbara Piccoli ${ }^{1}$
}

Published online: 24 January 2022

(c) The Author(s) under exclusive licence to Italian Society of Nephrology 2022

The term "lessons learnt" is increasingly appearing in medical journals in conjunction with COVID-19, coronavirus epidemic, or SARS-CoV-19: to date, 1727 articles on such lessons have been published (as a title or abstract) on PubMed. Although, in comparison with the approximately 8000 entries per year on dialysis, 7000 on colon cancer or 550 on IgA nephropathy, this number may appear insignificant, it does make it seem that learning has taken place.

Most of us would indeed like to learn from this experience, capitalizing on the terrible challenges we initially faced and the difficulties we continue to have to overcome every day, not to mention those minor annoyances that we have become used to-cleaning foggy eyeglasses or finding that hydro-alcoholic solution scrubs are causing the skin on our hands to crack.

The papers, submitted in waves, and describing what was happening around us, reflected what was happening during the past two troubled years. The first paper we published back in March 2020 was a heroic attempt by the Italian Society of Nephrology to summarize directions, and give practical indications on how to deal with the unexpected, overwhelming disaster. Looking at it now, it may seem almost naive, but its insistence on protecting patients, protecting the team and protecting the dialysis ward was innovative, considering that it was submitted before the World Health Organization had declared the existence of the pandemic, and in a context in which surgical masks were considered useless, and potentially dangerous as they might "scare" patients [1,2]. While many indications are no longer shared, and several have been added, this was one of the first position papers by a nephrology society in Europe.

The lockdown period was characterized by the submission of descriptions of local conditions, intended to describe

Giorgina Barbara Piccoli

gbpiccoli@yahoo.it

1 Nephrologie, Centre Hospitalier Le Mans, Avenue Roubillard 186, 72000 Le Mans, France the difficult problems that had had to be dealt with and the inventive solutions found: teams in Cremona, Genoa and the Piedmont region, to cite only a few, seemed to feel a need to share their experiences and report on their responses. When, in the early months of the pandemic, we decided to share patients' and young physicians' experiences, we thought that this should be done so that the period would not rapidly be forgotten, but at the time probably few of us thought that we would still be wondering about the evolution of "the beast" at the beginning of $2022[3,4]$.

Since then, from the point of view of computer screens first and journal pages later, we have witnessed the first attempts to gather large-scale information on the outcomes in our fragile patients all over the world, from Germany to Brazil, from the U.S. to Morocco, and the first interesting, outlier cases have been described: complex treatments, rare complications, exceptional conditions.

Case reports started appearing in ours such as other medical journals, often in the form of lessons for clinical nephrologists. Rather than the wish to teach ex-cathedra, they demonstrated a desire to avoid mistakes, and the need to gain time, while learning from scattered experiences, which were, however, the only ones then available. Many intuitions were favorable. Some suggested new treatment approaches, later summarized in commentaries or reviews in high-rank journals [5].

The availability of vaccines, their unforeseen side effects, and their indications are now being increasingly reported, while the current wave of the epidemics is likely to lead to submissions of reports on vaccine escape and consideration of future needs.

Papers on side effects and on the miracles being achieved using the new drugs will hopefully soon follow.

While, as editors, we are obliged to select from among the many reports submitted, as physicians and human beings we applaud all our colleagues who have sought to analyze and discuss their experiences, managing to write and engage in discussion at a moment when we often have very little time. 


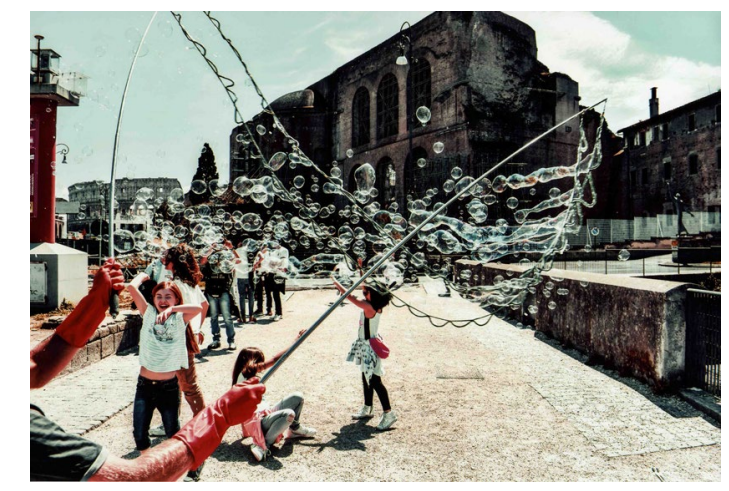

Fig. 1 Hope is a fragile soap bubble, which contains rainbows. This charming image was submitted to the Quirino Maggiore Price, an Italian price open to patients, families and health care staff, with the aim of promoting humanities in Nephrology. Courtesy of the Author (Emanuela Metafonti, dialysis nurse) and of the organizer (dr. Marco Lombardi). For information for the next edition, please refer to http://www.osmaonlus.org/concorso-nazionale-quirino-maggiore-2022/

We must do everything possible to avoid returning to the "inferno" of the early months of the pandemic [6].

What can be summarized from the lessons learnt in what we have published in these last 2 years?

Resilience, for sure; curiosity, and the desire to find new solutions; then that new alliances that may just have started to write a joint paper, may sometimes lead to a durable partnership. This be my wish for the new year (Fig. 1).

I know that this may seem simplistic and overly optimistic. We are human. We will disagree, we'll be jealous, we'll argue.

But let's hope that curiosity, resilience and liberty of mind can help us find new solutions and face the future challenges that we will ineluctably have to face, not only in fighting a new enemy, but also when using new technologies and reinforced alliances to disentangle old questions.
Funding None.

\section{Declarations}

Conflict of interest None.

Ethical approval No need for ethical approval for this editorial.

\section{References}

1. Rombolà G, Heidempergher M, Pedrini L, Farina M, Aucella F, Messa P, Brunori G (2020) Practical indications for the prevention and management of SARS-CoV-2 in ambulatory dialysis patients: lessons from the first phase of the epidemics in Lombardy. J Nephrol 33(2):193-196

2. https://www.ilsole24ore.com/art/da-inutili-obbligatorie-ancheall-aperto-cambio-rotta-mascherine-ADrrTSu?refresh_ce $=1$. Accessed Jan 2022

3. Picillo R, Seman A (2020) Reflections on life in the time of the coronavirus pandemic, from the viewpoint of two people who have experienced dialysis and kidney transplantation. J Nephrol. https://doi.org/10.1007/s40620-020-00731-2

4. Gambaro G, Piccoli GB, ICONA members (2020) Nothing will ever be as before. Reflections on the COVID-19 epidemics by nephrologists in eleven countries. J Nephrol 33(4):633-637

5. Bekassy Z, Lopatko Fagerström I, Bader M, Karpman D (2021) Crosstalk between the renin-angiotensin, complement and kallikrein-kinin systems in inflammation. Nat Rev Immunol 10:1-18. https://doi.org/10.1038/s41577-021-00634-8

6. Zerbi S, Resmini B, Merlino M, Licciardello C, Aloardi R, Palmetti D, Danelli L (2021) Inferno, disruption, concern, sense of community, teamwork, tears: reflections by renal healthcare team members on the front lines of the COVID-19pandemic. J Nephrol 34(1):7-10

Publisher's Note Springer Nature remains neutral with regard to jurisdictional claims in published maps and institutional affiliations. 